\title{
EFICIÊNCIA ENERGÉtICA EM EQUIPAMENTOS DE FORÇA-MOTRIZ
}

\section{Introdução}

A Eficiência Energética (EE) visa proporcionar o mesmo nível de produção de bens, serviços e de conforto através de tecnologias que reduzem os consumos face a soluções convencionais.

A EE pode conduzir a reduções substanciais do consumo de energia e das emissões de poluentes associadas à sua conversão. Em muitas situações a EE pode também conduzir a uma elevada economia nos custos do ciclo de vida dos equipamentos utilizadores de energia (custo inicial mais custo de funcionamento ao longo da vida útil).

Embora geralmente sejam mais dispendiosos, em termos de custo inicial, os equipamentos mais eficientes consomem menos energia, conduzindo a custos de funcionamento mais reduzidos e apresentando outras vantagens adicionais.

Neste âmbito, os motores elétricos, particularmente o motor assíncrono de indução, são o tipo de máquina mais utilizada na indústria em virtude da sua grande versatilidade, gama de potências, robustez, duração, reduzida manutenção, baixa poluição, facilidade de produção e custos de aquisição relativamente baixos.

Como qualquer máquina, o motor elétrico, responsável pela conversão de energia elétrica em mecânica, apresenta perdas. O rendimento (ou eficiência) é definido como sendo a razão entre a potência de saída (ao nível do veio de saída do acionamento) e a potência elétrica absorvida à entrada.

A produção de energia mecânica, através da utilização de motores elétricos, absorve cerca de $60 \%$ da energia elétrica consumida no sector industrial do nosso País, da qual apenas metade é energia útil. Este sector é, pois, um daqueles em que é preciso tentar fazer economias, prioritariamente.
O êxito neste domínio depende, em primeiro lugar, da melhor adequação da potência do motor à da máquina que ele aciona.

Quando o regime de funcionamento é muito variável, para permitir este ajustamento, pode-se equipar o motor com um conversor eletrónico de variação de velocidade.

Outra possibilidade é a utilização dos motores " de perdas reduzidas", de "alto rendimento", ou "elevada eficiência", que permitem economias energéticas consideráveis.

Nos últimos anos, muitos fabricantes de motores investiram fortemente na pesquisa e desenvolvimento de novos produtos com o objetivo de colocarem no mercado motores mais eficientes.

O acordo voluntário obtido em 1999 entre a CEMEP (Associação Europeia de Fabricantes de Motores Elétricos) e a Comissão Europeia sobre o rendimento de motores de 2 e 4 pólos, na gama de potências 1,1 a $90 \mathrm{~kW}$, foi revisto em 2004.

Os motores foram classificados de acordo com o seu rendimento:

- EFF1 - Motores de alto rendimento;

- EFF2 - Motores de rendimento aumentado;

- EFF3 - Motores sem qualquer requisito especial.

A norma CEI/EN 60034-30:2008 define três classes de eficiência IE (International Eficiency) para motores assíncronos de indução trifásicos, rotor em gaiola de esquilo, e velocidade simples:

- IE1: Eficiência Standard

(EFF2 do antigo sistema Europeu de classificação)

- IE2: Eficiência Elevada

(EFF1 do antigo sistema Europeu de classificação e idêntica à EPAct nos EUA para motores de $60 \mathrm{~Hz}$ ) 
- IE3: Eficiência Premium

(idêntica ao "NEMA Premium" nos E.U.A. para motores de $60 \mathrm{~Hz}$ )

- IE4: nível de eficiência superior a IE3

Os níveis de eficiência definidos na norma CEI/EN 6003430:2008 baseiam-se em métodos de ensaio especificados na norma CEI/EN 600034-2-1:2007. Comparando com as anteriores classes de rendimento Europeias, definidas pelo acordo CEMEP (norma CEI/EN 60034-2:1996), o leque foi ampliado.

A norma CEI/EN 60034-30 abrange quase todos os motores (por exemplo: motores standard, motores para ambientes perigosos, motores para embarcações e marinas, motores usados como freio), nomeadamente:

- Motores de velocidade simples, trifásicos, 50 e $60 \mathrm{~Hz}$

- Motores de 2, 4 ou 6 pólos

- Motores com potência nominal entre 0,75 - 375 kW

- Motores de tensão nominal até $1000 \mathrm{~V}$

- Motores do tipo Duty S1 (funcionamento em contínuo) ou S3 (funcionamento intermitente ou periódico) com um fator de duração cíclica nominal de 80 porcento ou superior.

\section{Caraterísticas dos motores de elevada eficiência}

A eficiência dos motores está associada a uma redução das suas perdas, que é conseguida à custa, quer da utilização de materiais construtivos de melhor qualidade e com melhores acabamentos, quer por alteração das suas características dimensionais.

Estas perdas são devidas aos diversos elementos que estão presentes na conversão eletromecânica de energia e podem ser divididas em quatro tipos:

- Perdas elétricas;

- Perdas magnéticas;

- Perdas mecânicas;

- Perdas parasitas.
As perdas elétricas são provocadas pela resistência não nula dos condutores das bobines que ao serem percorridos pela corrente provocam perdas caloríficas As perdas magnéticas ocorrem nas lâminas de ferro do estator e do rotor devido à histerese e às correntes de Foucault. As perdas mecânicas são provocadas pela rotação das peças móveis, ventilação e atrito do ar. As perdas parasitas são devidas a fugas e irregularidades de fluxo e, também, distribuição de corrente não uniforme.

Para melhorar a eficiência dos motores elétricos, os construtores aumentaram a massa de materiais ativos (cobre e ferro) de forma a diminuir as induções, as densidades de corrente e, assim, reduzir as perdas no cobre e no ferro.

Utilizam-se chapas magnéticas de perdas mais reduzidas, entalhes especiais em certos casos e reformulou-se a parte mecânica, com especial incidência sobre a ventilação, para reduzir a potência absorvida por esta e diminuir o nível de ruído.

Daí resulta, para idêntica dimensão, um aumento de peso da ordem de $15 \%$, e de preço da ordem de 20 a $25 \%$. Contudo, a melhoria da eficiência, compreendida entre 2 e 4,5\%, e do $\cos \phi$, permite amortizar rapidamente este aumento de preço.

As melhorias típicas que são efetuadas a nível construtivo da máquina podem ser visualizadas na Figura 1 e são resumidas na tabela 1.

Apesar de este tipo de motores possuir uma eficiência melhorada, quando inseridos num sistema, a eficiência total do mesmo sistema depende de todos os outros componentes que o compõem.

Por este motivo, não se deve apenas investir na compra de um motor de elevada eficiência, quando existirem problemas de eficiência nos outros componentes do sistema. 


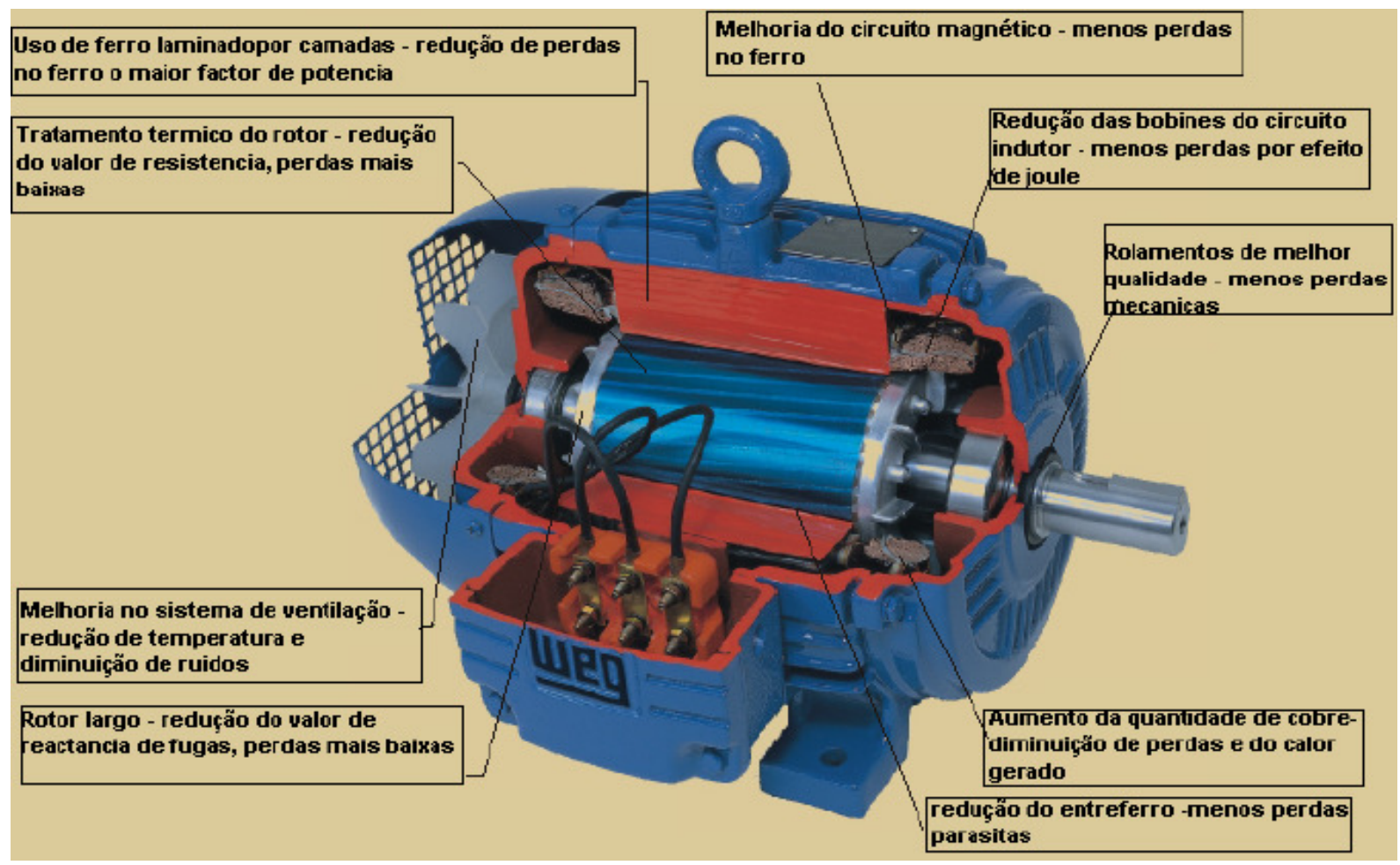

Figura 1. Alterações nos motores para obter elevada eficiência [fonte: WEG]

Tabela 1. Resumo das alterações nos motores de elevada eficiência

Alteração efetuada

Tratamento térmico do rotor

Uso de ferro laminado por camada

Melhoria do circuito magnético

Redução das bobines do circuito indutor

Melhor qualidade dos rolamentos

Maior quantidade de cobre

Redução do entre-ferro

Rotor mais largo

Sistema de ventilação melhorado

\section{Efeito produzido}

Redução da resistência

Redução das perdas no ferro

Redução das perdas no ferro

Redução das perdas por efeito de Joule

Redução das perdas mecânicas

Diminuição de perdas e do calor gerado

Diminuição das perdas parasitas

Reactância de fugas menor

Diminuição de ruídos e da temperatura 


\section{Classificação da eficiência energética}

$\mathrm{Na}$ Europa a classificação dos motores de corrente alternada de baixa tensão, foi estabelecida em 1998 com o acordo voluntário dos principais fabricantes de motores Europeus.

De uma forma resumida, o acordo estabelecido entre a Comissão Europeia (CE) e o Comité Europeu de Fabricantes de Máquinas Elétricas e de equipamentos e sistemas de Eletrónica de Potência (CEMEP) definia que os motores de 1,1 a 90 kW de potência nominal, 50 ou $60 \mathrm{~Hz}$, com 2 e 4 pólos magnéticos, seriam classificados de acordo com os valores dos respetivos rendimentos.

As classes de rendimento estabelecidas foram as seguintes:

- EFF1: Motores de elevado rendimento;

- EFF2: Motores de rendimento melhorado;

- EFF3: Motores de rendimento normal.

No acordo CE/CEMEP ficou ainda estabelecido que as vendas, na União Europeia, de motores EFF3 diminuiriam para metade até 2003.
Este objetivo foi alcançado e a venda de motores EFF3 terminou pouco tempo depois.

Todos os fabricantes que assinaram este acordo ficaram autorizados a colocar a etiqueta de eficiência nos motores e em toda a documentação que os acompanhe, o que tornou mais fácil a identificação da classe do motor.

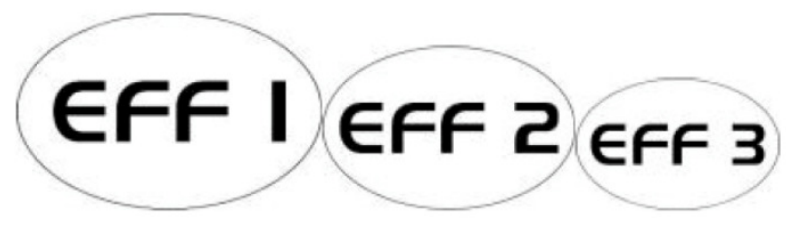

Figura 3. Etiquetas de eficiência dos motores

Com base no acordo voluntário anteriormente referido, foi também criada uma base de dados europeia EuroDEEM, que foi elaborada pelo centro de pesquisa da Comissão Europeia (CE/JRC), com o objetivo de reunir num só suporte as informações mais importantes sobre os motores elétricos disponíveis no mercado.

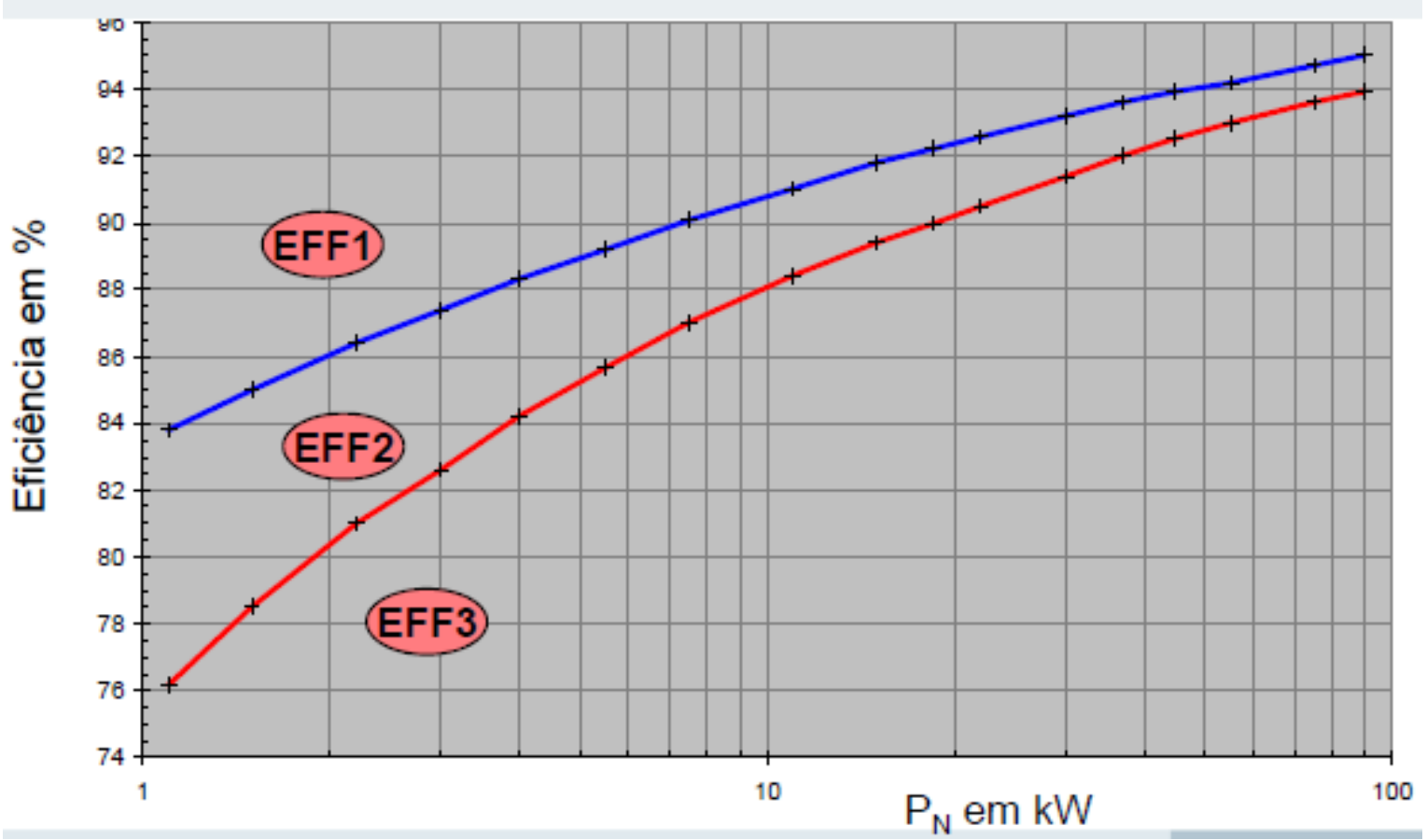

Figura 2. Classes de eficiência de motores. [Fonte: SEW-Eurodrive] 
A tabela 2 apresenta os valores limite para a eficiência dos motores, estabelecidos no acordo com a CEMEP com base na norma CEI 60034-2.

\section{Novas normas para classificação da eficiência energética}

A União Europeia, através do organismo EU MEPS (European

Minimum Energy Performance Standard), definiu um novo regime obrigatório para os níveis mínimos de eficiência dos motores elétricos que sejam introduzidos no mercado europeu.

O objetivo visa reduzir o consumo de energia e outros impactos ambientais negativos de produtos que consomem energia elétrica.

Ao mesmo tempo, pretende-se melhorar a uma escala global o nível de harmonização regulamentar em assuntos relacionados com a eficiência em equipamentos de forçamotriz.
Este novo regime abrange os motores de indução trifásicos, de velocidade simples, até $375 \mathrm{~kW}$. Entrou em vigor em três fases a partir de meados de 2011.

Sob este novo regime os fabricantes são obrigados a apresentar a classe e valores de eficiência do motor na respetiva chapa de características e na documentação do produto, que deve indicar claramente o método de teste usado na determinação da eficiência.

O organismo EU MEPS baseia-se em duas normas CEI:

- A norma CEI/EN 600034-2-1, disponível desde Setembro de 2007, introduz novas regras relativas aos métodos de teste que devem ser usados na determinação das perdas e da eficiência dos motores elétricos.

- A norma CEI/EN 600034-30, disponível desde outubro de 2008, especifica as classes de eficiência que devem ser adotadas.

Tabela 2. Definição das diversas classes de eficiência. Standard de 1996

\begin{tabular}{|c|c|c|c|c|}
\hline kW & $\begin{array}{c}\text { EFF3 } \\
2 \text { e } 4 \text { pólos } \\
\eta_{n}(\%)\end{array}$ & $\begin{array}{c}\text { EFF2 } \\
2 \text { e } 4 \text { pólos } \\
\eta_{n}(\%)\end{array}$ & $\begin{array}{c}\text { EFF1 } \\
2 \text { pólos } \\
\eta_{n}(\%)\end{array}$ & $\begin{array}{c}\text { EFF1 } \\
4 \text { pólos } \\
\eta_{n}(\%)\end{array}$ \\
\hline 1,1 & $<76,2$ & $\geq 76,2$ & $\geq 82,2$ & $\geq 83,8$ \\
\hline 1,5 & $<78,5$ & $\geq 78,5$ & $\geq 84,1$ & $\geq 85,0$ \\
\hline 2,2 & $<81,0$ & $\geq 81,0$ & $\geq 85,6$ & $\geq 86,4$ \\
\hline 3 & $<82,6$ & $\geq 82,6$ & $\geq 86,7$ & $\geq 87,4$ \\
\hline 4 & $<84,2$ & $\geq 84,2$ & $\geq 87,6$ & $\geq 88,3$ \\
\hline 5,5 & $<85,7$ & $\geq 85,7$ & $\geq 88,6$ & $\geq 89,3$ \\
\hline 7,5 & $<87,0$ & $\geq 87,0$ & $\geq 89,5$ & $\geq 90,1$ \\
\hline 11 & $<88,4$ & $\geq 88,4$ & $\geq 90,5$ & $\geq 91,0$ \\
\hline 15 & $<89,4$ & $\geq 89,4$ & $\geq 91,3$ & $\geq 91,8$ \\
\hline 18,5 & $<90,0$ & $\geq 90,0$ & $\geq 91,8$ & $\geq 92,2$ \\
\hline 22 & $<90,5$ & $\geq 90,5$ & $\geq 92,2$ & $\geq 92,6$ \\
\hline 30 & $<91,4$ & $\geq 91,4$ & $\geq 92,9$ & $\geq 93,2$ \\
\hline 37 & $<92,0$ & $\geq 92,0$ & $\geq 93,3$ & $\geq 93,6$ \\
\hline 45 & $<92,5$ & $\geq 92,5$ & $\geq 93,7$ & $\geq 93,9$ \\
\hline 55 & $<93,0$ & $\geq 93,0$ & $\geq 94,0$ & $\geq 94,2$ \\
\hline 75 & $<93,6$ & $\geq 93,6$ & $\geq 94,6$ & $\geq 94,7$ \\
\hline 90 & $<93,9$ & $\geq 93,9$ & $\geq 95,0$ & $\geq 95,0$ \\
\hline
\end{tabular}


A norma CEI/EN 600034-2-1:2007 define duas formas de determinar a eficiência dos motores elétricos, o método direto e os métodos indiretos.

A norma especifica os seguintes parâmetros para determinar a eficiência pelo método indireto:

- Temperatura de referência;

- Três opções para determinar as perdas adicionais em carga: medição, estimativas e cálculo matemático.

Os valores de eficiência resultantes diferem daqueles obtidos sob o padrão anterior de teste baseados na norma CEI/EN 60034-2:1996.

Deve-se notar que os valores de eficiência só são comparáveis se forem medidos utilizando o mesmo método.

A norma CEI/EN 60034-30:2008 define três classes de eficiência IE (International Eficiency) para motores assíncronos de indução trifásicos, rotor em gaiola de esquilo, e velocidade simples:

- IE1: Eficiência Standard

(EFF2 do antigo sistema Europeu de classificação)

- IE2: Eficiência Elevada

(EFF1 do antigo sistema Europeu de classificação e idêntica à EPAct nos EUA para motores de $60 \mathrm{~Hz}$ )

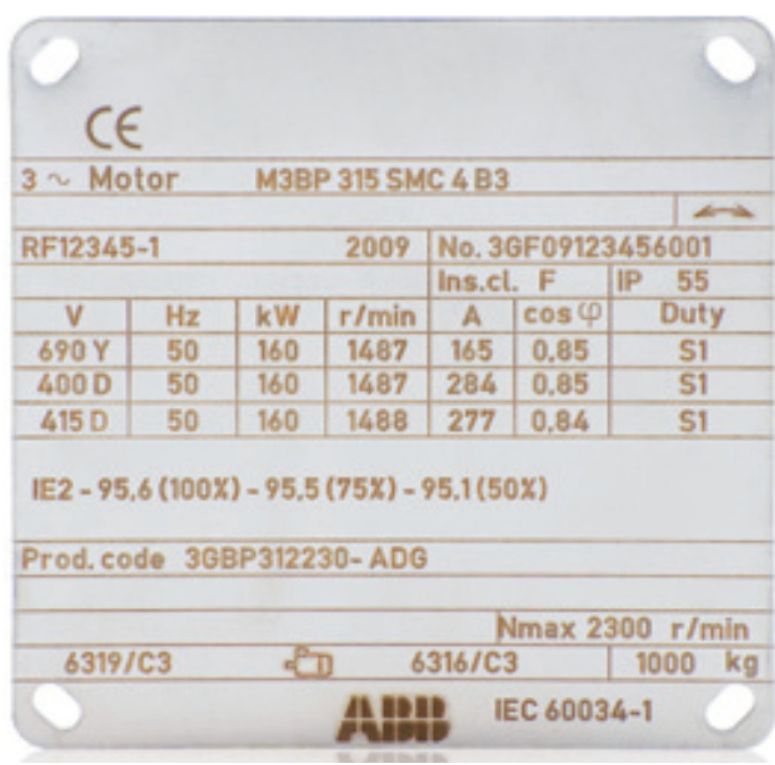

Figura 4. Chapa de características de motor ABB, de acordo com as novas normas

- IE3: Eficiência Premium (idêntica ao "NEMA Premium" nos E.U.A. para motores de $60 \mathrm{~Hz}$ )

- IE4: Nível de eficiência superior a IE3

Os níveis de eficiência definidos na norma CEI/EN 6003430:2008 baseiam-se em métodos de ensaio especificados na norma CEI/EN 600034-2-1:2007.

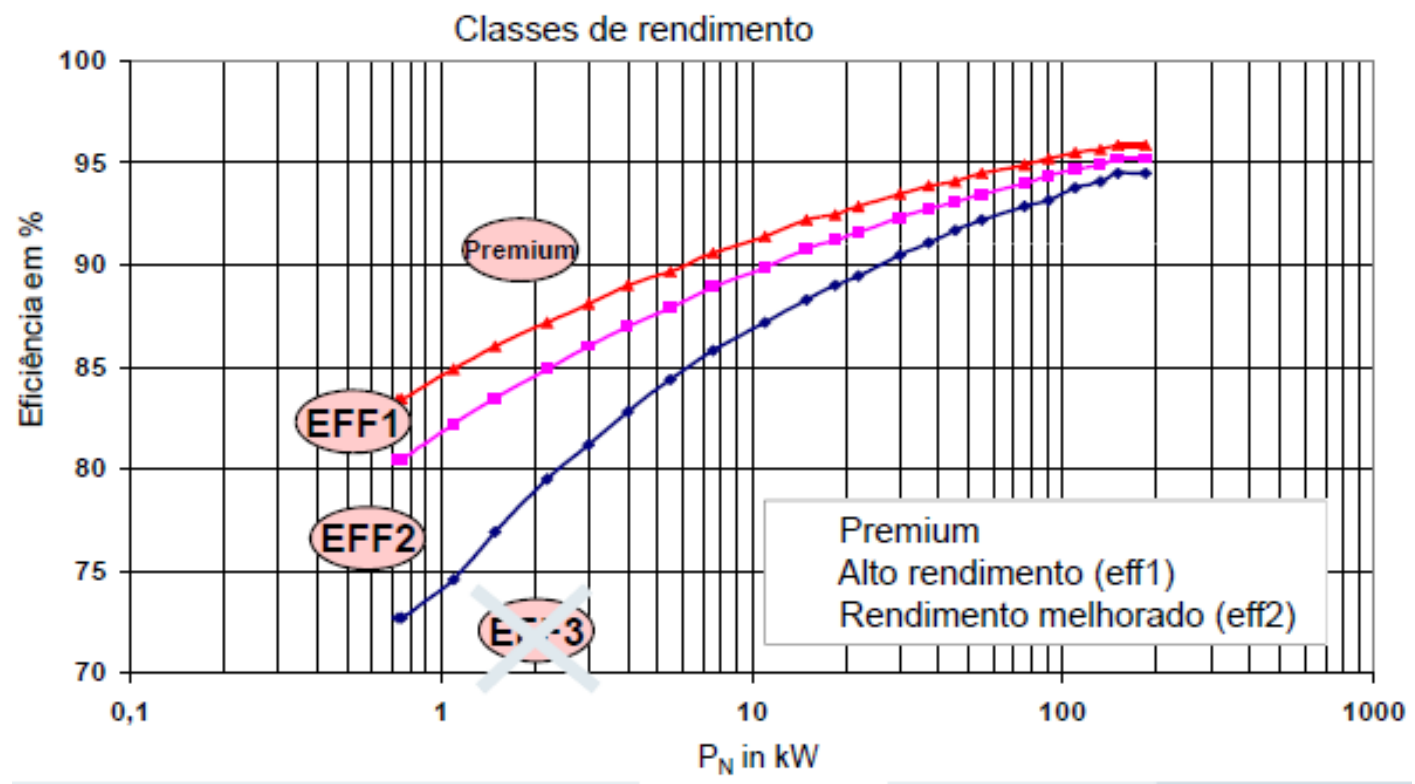

Figura 5. Novas classes de eficiência de motores. [SEW-Eurodrive] 
Comparando com as anteriores classes de rendimento Europeias, definidas pelo acordo CEMEP (norma CEI/EN 60034-2:1996), o leque foi ampliado.

A norma $\mathrm{CEI} / \mathrm{EN}$ 60034-30 abrange quase todos os motores (por exemplo: motores standard, motores para ambientes perigosos, motores para embarcações e marinas, motores usados como freio), nomeadamente:

- Motores de velocidade simples, trifásicos, 50 e $60 \mathrm{~Hz}$

- Motores de 2, 4 ou 6 pólos

- Motores com potência nominal entre 0,75-375 kW

- Motores de tensão nominal até $1000 \mathrm{~V}$

- Motores do tipo Duty S1 (funcionamento em contínuo) ou S3 (funcionamento intermitente ou periódico) com um fator de duração cíclica nominal de 80 porcento ou superior.

Os motores que estão excluídos das normas CEI/EN 60034-30 são os seguintes:

- Motores feitos exclusivamente para funcionarem como conversores.
- Motores feitos exclusivamente para funcionarem imersos em líquidos.

- Motores totalmente integrados em máquinas que não podem ser testados separadamente da máquina (por exemplo, bombas, ventiladores ou compressores).

- Motores especificamente concebidos para funcionarem a altitudes superiores a 1000 metros. Onde as temperaturas do ar possam ultrapassar os $40{ }^{\circ} \mathrm{C}$. Em temperaturas máximas superiores a $400{ }^{\circ} \mathrm{C}$. Onde a temperatura ambiente for inferior a $-15{ }^{\circ} \mathrm{C}$ (qualquer motor) ou inferior a $0{ }^{\circ} \mathrm{C}$ (motores refrigerados a ar). Onde a temperatura da água de arrefecimento na entrada de um produto é inferior a $5 \quad{ }^{\circ} \mathrm{C}$ ou superior a $25{ }^{\circ} \mathrm{C}$. Em atmosferas potencialmente explosivas, tal como definido na Directiva 94/9/CE.

Na tabela 3 apresenta-se os valores limite para a eficiência dos motores com base na norma CEI 60034-30:2008,e CEI/EN 600034-2-1.

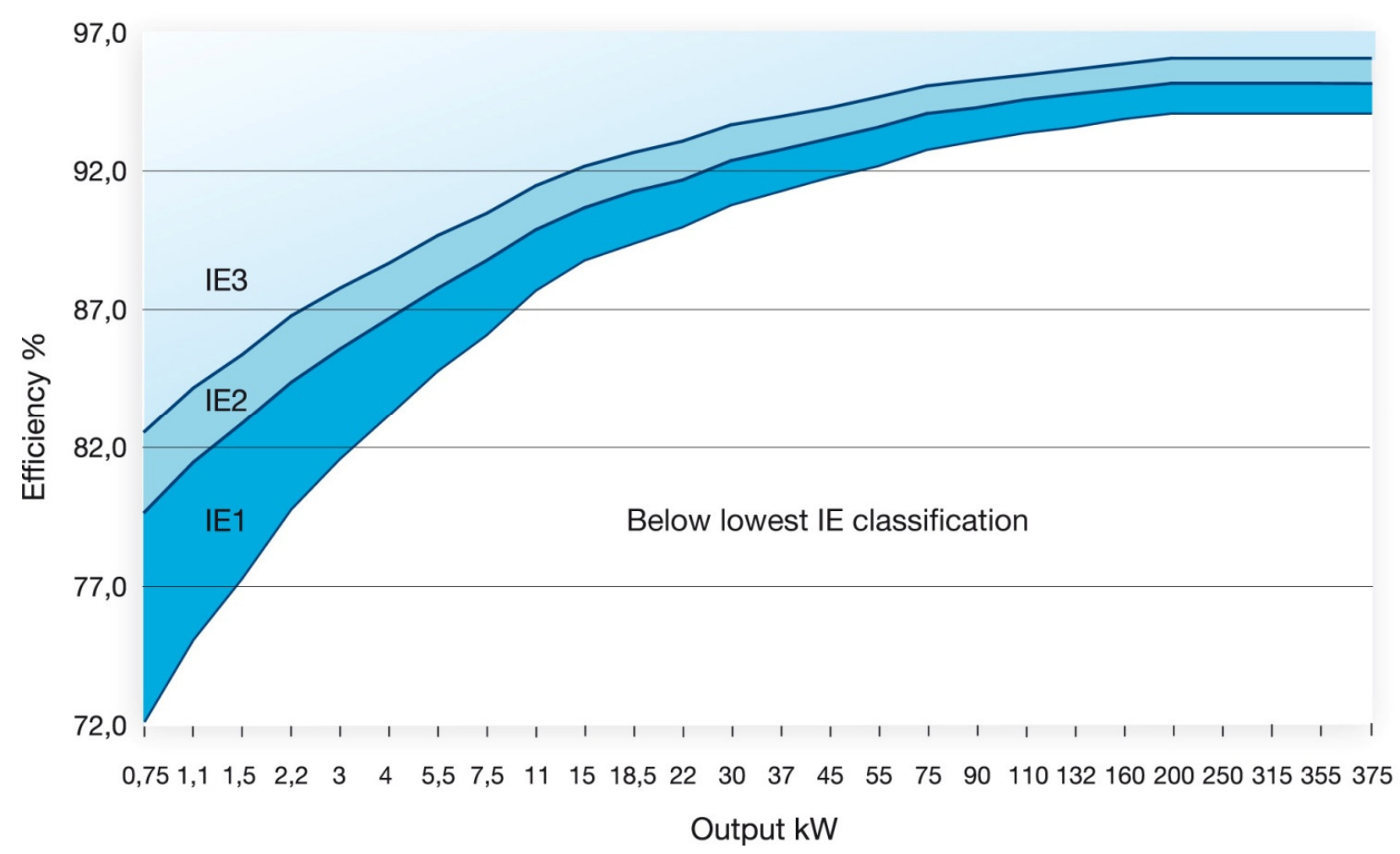

Figura 6. Novas classes IE de eficiência de motores elétricos 
Tabela 3. Definição das diversas classes de eficiência

Normas CEI 60034-30:2008,e CEI/EN 600034-2-1

[Fonte: ABB]

\begin{tabular}{|c|c|c|c|c|c|c|c|c|c|}
\hline $\begin{array}{l}\text { Out- } \\
\text { put } \\
\mathrm{kw} \\
\end{array}$ & $\begin{array}{l}\text { IE1 } \\
\text { Standa } \\
2 \text { pole }\end{array}$ & $\begin{array}{l}\text { ard effic } \\
4 \text { pole }\end{array}$ & $\begin{array}{l}\text { ciency } \\
6 \text { pole }\end{array}$ & $\begin{array}{l}\text { IE2 } \\
\text { High of } \\
2 \text { pole } \\
\end{array}$ & $\begin{array}{l}\text { fficienc) } \\
4 \text { pole }\end{array}$ & $\begin{array}{l}y \\
6 \text { pole }\end{array}$ & $\begin{array}{l}\text { IE3 } \\
\text { Premiu } \\
2 \text { pole }\end{array}$ & $\begin{array}{l}\text { um effici } \\
4 \text { pole }\end{array}$ & $\begin{array}{l}\text { iency } \\
6 \text { pole } \\
\end{array}$ \\
\hline 0.75 & 72.1 & 72.1 & 70.0 & 77.4 & 79.6 & 75.9 & 90.7 & 82.5 & 78.9 \\
\hline 1.1 & 75.0 & 75.0 & 72.9 & 79.6 & 81.4 & 78.1 & 82.7 & 84.1 & 81.0 \\
\hline 1.5 & 77.2 & 77.2 & 75.2 & 81.3 & 82.8 & 79.8 & 84.2 & 85.3 & 82.5 \\
\hline 2.2 & 79.7 & 79.7 & 77.7 & 83.2 & 84.3 & 81.8 & 85.9 & 86.7 & 84.3 \\
\hline 3 & 81.5 & 81.5 & 79.7 & 84.8 & 85.5 & 83.3 & 87.1 & 87.7 & 85.6 \\
\hline 4 & 83.1 & 83.1 & 81.4 & 85.8 & 86.6 & 84.6 & 88.1 & 88.6 & 88.8 \\
\hline 5.5 & 84.7 & 84.7 & 83.1 & 87.0 & 87.7 & 86.0 & 89.2 & 89.6 & 89.0 \\
\hline 7.5 & 86.0 & 86.0 & 84.7 & 88.1 & 88.7 & 87.2 & 90.1 & 90.4 & 89.1 \\
\hline 11 & 87.6 & 87.6 & 86.4 & 89.4 & 89.8 & 88.7 & 91.2 & 91.4 & 90.3 \\
\hline 15 & 88.7 & 88.7 & 87.7 & 90.3 & 90.6 & 89.7 & 91.9 & 92.1 & 91.2 \\
\hline 18.5 & 89.3 & 89.3 & 88.6 & 90.9 & 91.2 & 90.4 & 92.4 & 92.6 & 91.7 \\
\hline 22 & 89.9 & 89.9 & 89.2 & 91.3 & 91.6 & 90.9 & 92.7 & 93.0 & 92.2 \\
\hline 30 & 90.7 & 90.7 & 90.2 & 92.0 & 92.3 & 91.7 & 93.3 & 93.6 & 92.9 \\
\hline 37 & 91.2 & 91.2 & 90.8 & 92.5 & 92.7 & 92.2 & 93.7 & 93.9 & 93.3 \\
\hline 45 & 91.7 & 91.7 & 91.4 & 92.9 & 93.1 & 92.7 & 94.0 & 94.2 & 93.7 \\
\hline 55 & 92.1 & 92.1 & 91.9 & 93.2 & 93.5 & 93.1 & 94.3 & 94.6 & 94.1 \\
\hline 75 & 92.7 & 92.7 & 92.6 & 93.8 & 94.0 & 93.7 & 94.7 & 95.0 & 94.6 \\
\hline 90 & 93.0 & 93.0 & 92.9 & 94.1 & 94.2 & 94.0 & 95.0 & 95.2 & 94.9 \\
\hline 110 & 93.3 & 93.3 & 93.3 & 94.3 & 94.5 & 94.3 & 95.2 & 95.4 & 95.1 \\
\hline 132 & 93.5 & 93.5 & 93.5 & 94.6 & 94.7 & 94.6 & 95.4 & 95.6 & 95.4 \\
\hline 160 & 93.7 & 93.8 & 93.8 & 94.8 & 94.9 & 94.8 & 95.6 & 95.8 & 95.6 \\
\hline 200 & 94.0 & 94.0 & 94.0 & 95.0 & 95.1 & 95.0 & 95.8 & 96.0 & 95.8 \\
\hline 250 & 94.0 & 94.0 & 94.0 & 95.0 & 95.1 & 95.0 & 95.8 & 96.0 & 95.8 \\
\hline 315 & 94.0 & 94.0 & 94.0 & 95.0 & 95.1 & 95.0 & 95.8 & 96.0 & 95.8 \\
\hline 355 & 94.0 & 94.0 & 94.0 & 95.0 & 95.1 & 95.0 & 95.8 & 96.0 & 95.8 \\
\hline 375 & 94.0 & 94.0 & 94.0 & 95.0 & 95.1 & 95.0 & 95.8 & 96.0 & 95.8 \\
\hline
\end{tabular}

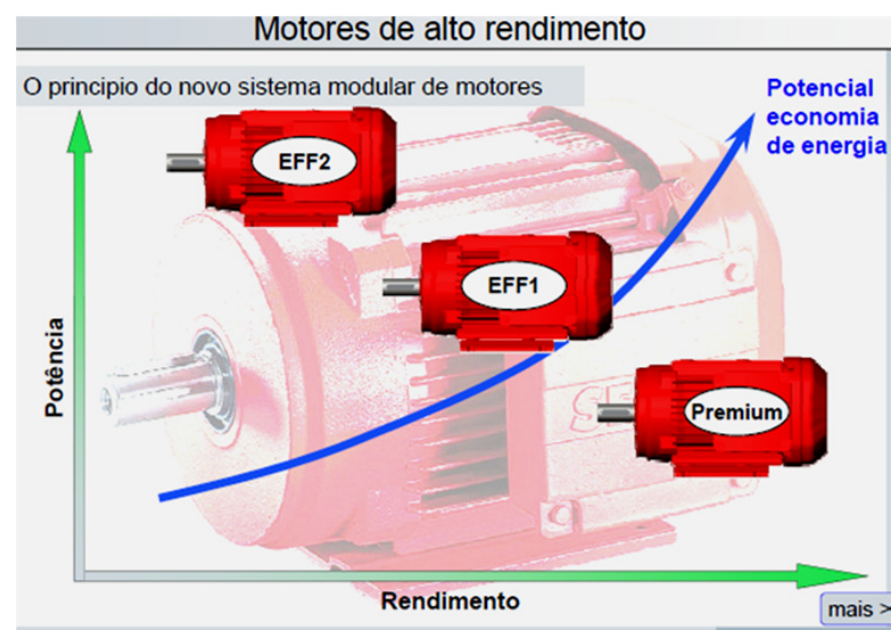

Figura 7. Variação do rendimento com a potência

[Fonte: SEW-Eurodrive]

\section{Variadores eletrónicos de velocidade}

Uma grande parte das aplicações em que se utiliza força motriz beneficia, em termos de consumo de energia elétrica e de desempenho global, se a velocidade do motor se ajustasse às necessidades do processo.

A utilização de variadores eletrónicos de velocidade (VEVs) permite responder a alterações nas condições de carga do motor através da variação da sua velocidade.

Por exemplo os VEVs podem substituir com larga vantagem dispositivos de estrangulamento de caudais utilizados em muitas aplicações na Indústria.

Através da regulação da velocidade de rotação dos motores, os VEVs proporcionam uma melhoria das condições de funcionamento dos processos, um menor desgaste dos componentes mecânicos, um menor ruído de funcionamento e, fundamentalmente, uma substancial poupança de eletricidade.

A adoção de variadores eletrónicos para regular a velocidade das máquinas rotativas é, atualmente, a solução mais eficiente, apresentando os seguintes benefícios:

- economia de energia;

- aumento da produtividade;

- melhoria da qualidade do produto;

- $\quad$ menor desgaste mecânico.

Assim, em aplicações onde sejam requeridas apenas duas ou três velocidades, é aconselhável a utilização de motores assíncronos de velocidades variáveis, disponíveis com diversos tipos de características de binário/velocidade, e por isso adaptáveis a diversos tipos de carga. 
Nestes sistemas, a aplicação de variadores eletrónicos de velocidade, bem como de equipamentos mais eficientes do ponto de vista energético, permite elevar o rendimento global dos sistemas de $31 \%$ para $72 \%$, com tempos de recuperação do investimento normalmente inferiores a três anos.

Os VEVs, para além de permitirem efetuar arranques suaves, proporcionando um menor desgaste mecânico e elétrico do equipamento, implementam uma série de proteções ao motor, como proteção contra curto-circuitos, sobreintensidades, sobretensões e falta de fase, que deste modo não precisam ser adquiridas separadamente, podendo facilmente ser integrados em sistemas automáticos de gestão da produção.

Existem diversos tipos de configurações do circuito eletrónico dos VEVs, consoante o tipo de motor e a gama de potência. A maioria dos VEVs é baseada em conversores ACDC-AC (figura 8).

A figura 9 mostra a potência elétrica absorvida por uma bomba com controlo de caudais por válvula de estrangulamento e por controlo de velocidade.

Pode observar-se uma diferença considerável da potência entre os dois métodos, à medida que o caudal decresce.

Outros tipos de cargas (ventiladores, compressores) apresentam um comportamento semelhante.

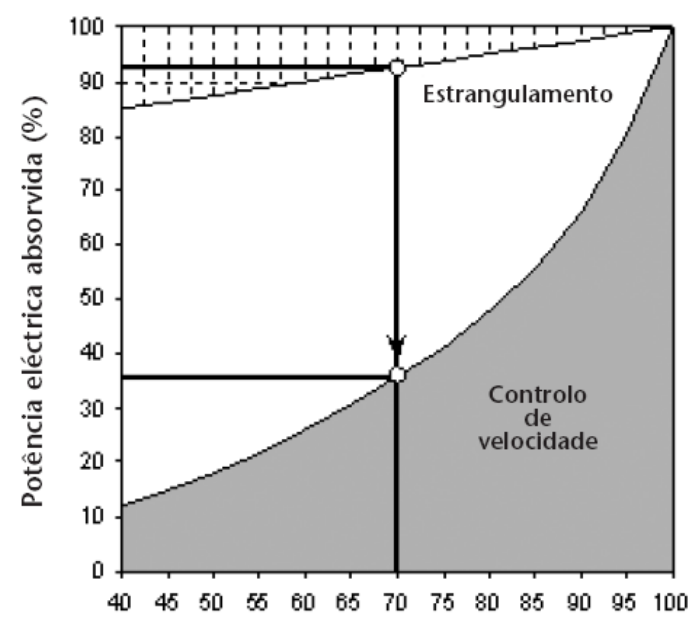

(a) caudal (\%)

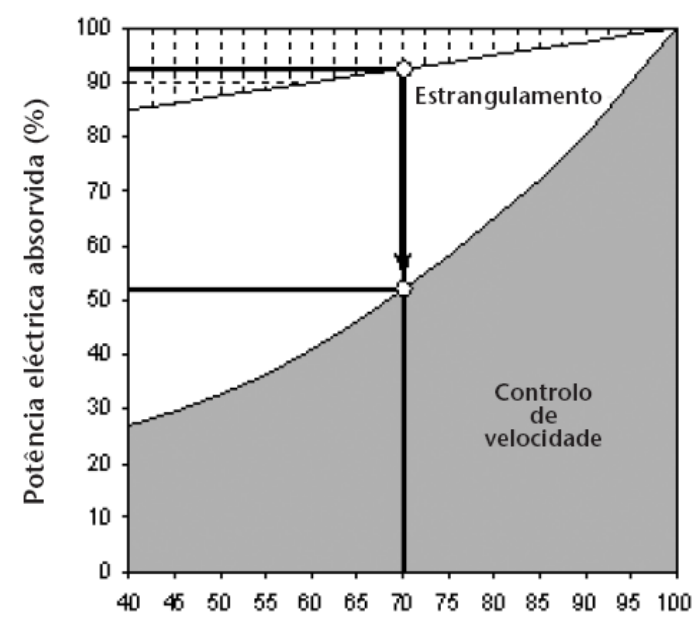

(b) caudal (\%)

Figura 9. Potência elétrica absorvida por uma bomba com controlo de caudais por válvula de estrangulamento e por controlo de velocidade (a) sem elevação (b) com elevação [BCSD -Portugal]

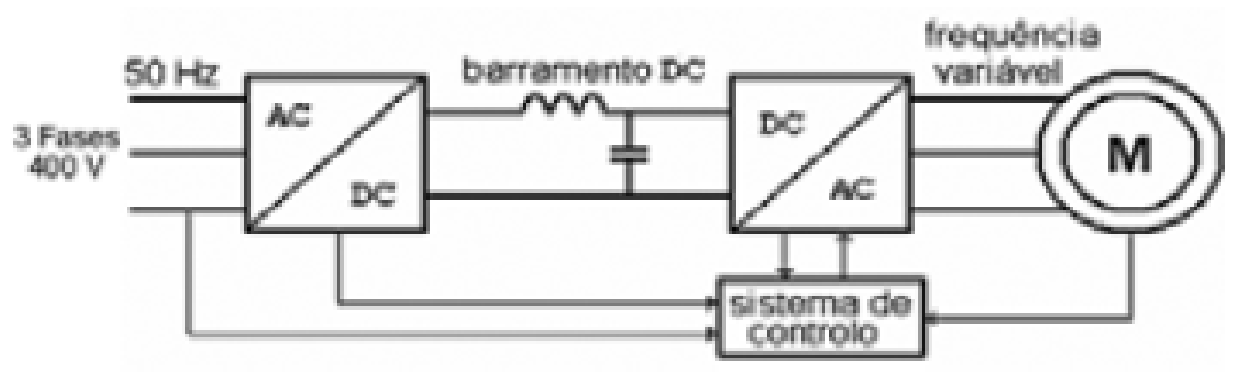

Figura 8. Diagrama de um variador eletrónico de velocidade [BCSD -Portugal] 


\section{Considerações finais}

A produção de energia mecânica, através da utilização de motores elétricos, absorve cerca de $60 \%$ da energia elétrica consumida no sector industrial do nosso País, da qual apenas metade é energia útil.

Este sector é, pois, um daqueles em que é preciso tentar fazer economias, prioritariamente.

Os sistemas de acionamentos eletromecânicos têm que ser abordados como um todo, já que a existência de um componente de baixo rendimento influencia drasticamente o rendimento global.

Os pontos fundamentais em que se deve intervir são os seguintes:

- Dimensionar corretamente os equipamentos de força motriz, fazendo os motores funcionar com cargas da ordem dos 70 a $80 \%$.

- Adaptar a velocidade do motor às necessidades do processo, utilizando sempre que necessário dispositivos eletrónicos de variação de velocidade.

- Atender às necessidades de manutenção dos motores, que são essencialmente a limpeza da carcaça, a fim de reduzir a temperatura, e nalguns casos a lubrificação dos rolamentos.

- Utilizar os novos motores de "alto rendimento", que já provaram a sua competitividade apesar do seu custo superior, devendo-se ponderar sempre que necessário a sua utilização.

A União Europeia, através do organismo EU MEPS (European Minimum Energy Performance Standard) definiu um novo regime obrigatório para os níveis mínimos de eficiência dos motores elétricos que sejam introduzidos no mercado europeu.

O novo regime abrange motores de indução trifásicos até $375 \mathrm{~kW}$, de velocidade simples. Entrou em vigor em três fases a partir de 2011.
Sob este novo regime os fabricantes são obrigados a apresentar os valores IE (International Eficiency) classe de eficiência nas placas do motor e na documentação do produto.

O organismo EU MEPS assenta em duas normas CEI.

- A norma CEI/EN 600034-2-1, disponível desde Setembro de 2007, introduz novas regras relativas aos métodos de teste que devem ser usados na determinação das perdas e da eficiência dos motores elétricos.

- A norma CEI/EN 600034-30,disponível desde Outubro de 2008, especifica as classes de eficiência que devem ser adotadas.

De acordo com estas normas os motores passam a ser classificados por:

- IE1 (equivalente a EFF2 na norma CEI/EN 6000342:1996) - com utilização proibida;

- IE2 (equivalente a EFF1 na norma CEI/EN 6000342:1996) - com utilização obrigatória;

- IE3 (Premium) - com utilização voluntária;

- IE4 (ainda não aplicável a acionamentos assíncronos).

Os motores de eficiência (IE1) deixam de ser colocados no mercado europeu a partir de 16 de Junho de 2011. Até aquela data todos os novos motores em avaliação na Europa tiveram de cumprir a eficiência IE2.

As regras não se aplicam fora da Europa. Por isso, será possível que os fabricantes produzam motores com eficiência IE1 para os mercados que não exijam estes requisitos mínimos de eficiência.

A conformidade com os padrões de eficiência exigidos é verificada por ensaios.

Cabe a cada estado membro da UE a vigilância relativa aos procedimentos de verificação e implementação das normas. 
A implementação das novas normas em cada estado membro de EU foi realizada em três fases:

- $\quad$ Fase 1: até 16 de Julho de 2011

Todos os motores satisfazem o nível de eficiência IE2;

- Fase 2: até 1 de Janeiro de 2015 Todos os motores com uma potência nominal entre 7,5 - 375 kW satisfazem o nível de eficiência IE3 ou o nível IE2 se equipados com um variador eletrónico de velocidade;

- Fase 3: até 1 de Janeiro de 2017 Todos os motores com uma potência nominal entre 0,75-375 kW satisfazem o nível de eficiência IE3 ou o nível IE2 se equipados com um variador eletrónico de velocidade.

\section{Referências}

- Beleza Carvalho, J. A. Máquinas Assíncronas de Indução. Aulas de máquinas Elétricas. Instituto Superior de Engenharia do Porto.
- Beleza Carvalho, J. A. Utilização Racional de Energia em Equipamentos de Força Motriz. Revista Neutro à Terra № 11, Junho de 2013.

- Beleza Carvalho, J. A., Mesquita Brandão, R. F. Acionamentos Eficientes de Força-Motriz. Nova Classificação. Revista Neutro à Terra № 10, Junho de 2010.

- Beleza Carvalho, J. A., Mesquita Brandão, Eficiência Energética em Equipamentos de Força Motriz. Jornadas Luso-Brasileiras de Ensino e Tecnologia em Engenharia. ISEP, Porto, Fevereiro de 2009.

- Beleza Carvalho, J. A., Mesquita Brandão, R. F., Efficient Use of Electrical Energy in Industrial Installations. 4TH European Congress Economics and Management of Energy in Industry. Porto, Novembro de 2007.

- ABB, Low Voltage Industrial Performance Motors. Catálogo ABB 2009.

- Manual De Boas Práticas De Eficiência Energética. BCSD Portugal.
Água quente sanitária (AQS): a água potável aquecida em dispositivo próprio, com energia convencional ou renovável, até uma temperatura superior a $45^{\circ} \mathrm{C}$, e destinada a banhos, limpezas, cozinha ou fins análogos.

Avaliação energética: a avaliação detalhada das condições de exploração de energia de um edifício ou fração, com vista a identificar os diferentes vetores energéticos e a caracterizar os consumos energéticos, podendo incluir, entre outros aspetos, o levantamento das características da envolvente e dos sistemas técnicos, a caracterização dos perfis de utilização e a quantificação, monitorização e a simulação dinâmica dos consumos energéticos.

Certificado SCE: o documento com número próprio, emitido por perito qualificado para a certificação energética para um determinado edifício ou fração, caracterizando-o em termos de desempenho energético.
Edifício: a construção coberta, com paredes e pavimentos, destinada à utilização humana.

Ventilação natural: a ventilação ao longo de trajetos de fugas e de aberturas no edifício, em consequência das diferenças de pressão, sem auxílio de componentes motorizados de movimentação do ar.

Ventilação mecânica: aquela que não seja ventilação natural.

Perito qualificado (PQ): o técnico com título profissional de perito qualificado para a certificação energética, nos termos da Lei n.o 58/2013, de 20 de agosto.

Técnico autor do projeto: o técnico legalmente habilitado para realizar o projeto e responsável pelo cumprimento da legislação aplicável. 